\title{
Sobre una Alusión Literaria en la Novela Pax
}

La aparición de la novela $P a x$ en Bogotá, en 1907 , fue un verdadero acontecimiento literario. Era el fruto de la colaboración del afamado José María Rivas Groot con el académico Lorenzo Marroquín, autor de la mayoría de las páginas. La novela alcanzó una popularidad inmediata, no igualada hasta hory en las letras colombianas. Los encuadernadores no daban abasto a la demanda del público, y se publicaron dos grandes ediciones en menos de dos meses, suceso casi inaudito en Hispanoamérica. Pocos años más tarde salieron dos ediciones de Pax en París, cumpliéndose así el sueño de todo escritor latinoamericano de interés: una edición de su obra publicada en la Ciudad Luz. Algunos años después se hizo una traducción inglesa. Un comentador contemporáneo describe la popularidad obtenida por la novela en Colombia: "... los admiradores de $P a x$, que son este mundo y el que está por descubrir, en lugar de sombrero se ponen la novela sobre la cabeza, exaltan hasta las estrellas el estilo del librote y tratan de arcaísmo ridículo y de purismo despreciable todo lo que no concierta con los abigartados colores que guarda Pax en su cajón"." Se encendieron los ánimos a causa de la novedad literaria, y los amigos y los detractores de Pax llenaron la prensa de elogios encomiásticos y de censuras mordaces durante mucho tiempo. ${ }^{2}$ A los tres meses de publicarse Pax, salió de la pluma del renombrado académico, y más tarde Presidente de la República, Marco Fidel Suárez, un Análisis gramatical de "Pax", largo estudio de más de doscientas páginas, cuyo objeto era poner de manifiesto las incorrecciones de la prosa de Marroquín.

1 Citado en Análisis gramatical de "Pax", por un sobrino de D. Ramón González Mogollón [pseudónimo de Marco Fidel Suárez] (Bogotá, 1907), p. 200.

2 Véase la bibliografía citada por Antonio Curcio Altamar, Evolución de la novela en Colombia (Bogotá, 1957), pp. 183-187. 
Sin embargo, no es Pax una novela de gran importancia, aunque haya quien opine que "debe figurar entre las primeras novelas del Con. tinente". ${ }^{3}$ Desde I9I 2 no ha tenido sino una sola edición en español. La inmensa y efímera popularidad de Pax no se debe a su valor literario, sino al hecho de que es una novela de clave. A pesar de que Marroquín, siguiendo el ejemplo de Le Sage y Daudet, declara que su novela no tiene clave, y que sus personajes no deben identificarse con personas vivientes, todo el mundo vio retratadas ahí a muchas de las importantes figuras de la política colombiana contemporánea. Y es evidente que el público tenía razón: a pesar de las protestas de Marroquín, no era difícil identificar varias de sus caricaturas con seres reales. Otros personajes son puras invenciones, o figuras que combinan características de diferentes personas conocidas, sin llegar a ser el retrato de nadie en particular. No nos interesa Pax aquí por sus alusiones políticas, sino por su referencias a escritores coetáneos.

Varios críticos ya se han fijado en el poeta S. C. Mata, personaje importantísimo de la novela, y han visto en él una caricatura de José Asunción Silva." Convendrá prestar atención a estas alusiones, para poder precisar si se trata o no, en efecto, de una caricatura de Silva. ${ }^{5}$

La primera mención de S. C. Mata aparece en el capítulo I de Pax, donde sabemos que es editor de una revista literaria: La Pagoda de Nietzsche. En el capitulo siguiente se presentan trozos, versos y prosa, de la obra de Mata. Los versos se titulan "Nostalgia egipcia" y expresan el deseo del poeta de morir en la patria de Cleopatra, en medio de los esplendores de esa civilización pagana:

En el triunfo cenizo de evanescentes pintas,

Al surgir la apoteosis para las medias tintas,

Yo quiero que se rompa el canto de mi lira

Junto a la fija Esfinge, que mira, mira, mira,

$Y$ en el arenal cálido, que un sueño blanco finge,

Ser el eterno novio de la silente Esfinge,

3 Luis Alberto Sánchez, Proceso y contenido de la novela Hispano-Americana (Madrid, 1953), p. 365.

4 Según José J. Ortega Torres, "desde el primer instante, la crítica señaló... en el poeta S. C. Mata, a José Asunción Silva..." ("Anotaciones bibliográficas", en José María Rivas Groot, Páginas escogidas [Bogotá, 1943], p. 38).

5 Hay otra caricatura literaria en Pax, pero por ser figura de mínima importancia artística, no nos ocuparemos en detalle de ella. Se trata de doña Aura del Campo de Cardoso, feminista militante y novelista de larga producción, bien que de corto ingenio. Es obvio para todo conocedor de la literatura colombiana que la escritora caricaturizada es la prolifiquísima doña Soledad Acosta de Samper. 
Alli do el sol, lustrando les oros de su magia,

Desata la escarlata de su roja hemorragia;

Do erigen los camellos el cuello corvo y largo

Cual los interrogantes de un gran poema amargo;

$Y$ donde las jirafas alzan el cuello recto

Cual las admiraciones de un dístico perfecto;

La parodia de los motivos del Modernismo - el uso de colores, las referencias a tierras lejanas y exóticas, el interrogante que forma el cuello del cisne, etc.- está bastante lograda, a pesar de su humor un poco tosco y vulgar, y no necesita comentario. En el capítulo XV tenemos el final del poema, donde Mata se mofa del cristianismo, y más particularmente, del catolicismo:

No me pongan maderos de cuatro ángulos rectos Que tienen los cristianos en sus tumbas erectos.

$\mathrm{Ra}$ vele alli mi sueño. Ra, el gran dios del dominio, Ese sueño de momia de que nos habla Plinio.

$Y$ también me acompañe Keth, la divina Gata

Con sus ojos de fósforo y su sonrisa chata.

¡Cuánto mejor que monjes y romanos pontífices,

Tener de Phat-Hotep los divinos artífices!

Y cúbrame la sombra, en el imperio Idea,

De Patch, que con su testa de leona muequea.

$\mathrm{Y}$ el Buey Apis, el bruto más santo de los brutos,

Que sus cuernos eglógicos tuerce en corvos volutes.

.......................... (p. 224)

Lo primero que nos llama la atención al examinar este poema es el metro: son alejandrinos pareados, un metro de uso muy limitado. En seguida recordamos que es el mismo empleado por Silva en "Un Poema"; no cabe duda de que la coincidencia es intencionada. Todavía más significativo es el hecho de que Guillermo Valencia vertió su famoso "Leyendo a Silva" en el molde del alejandrino pareado. Está claro que la alusión no es a Valencia, sino a Silva; lo que tenemos aquí es un "Leyendo a Silva" vuelto al revés; en vez de alabanza encarecida, crítica acerba. Que toda la saña de Rivas Groot? va dirigida contra el poeta

6 Pp. 26.27 de la ed. de la Biblioteca Popular de Cultura Colombiana, $\mathrm{n}^{\circ} 76$ (Bogotá, 1946). Las citas subsiguientes serán de esta edición.

7 Tratándose de una colaboración, es difícil precisar lo que escribió Marroquín y lo que corresponde a Rivas Groot. Sin embargo, los rasgos modernistas de la obra de Mata nos hacen creer que ésta es fruto de la pluma de Rivas Groot. Además, las constantes referencias a temas musicales y culturales que se 
suicida se ve en el tema predominante del poema, el de la muerte. Es notoria la preocupación de Silva por la muerte; constituye uno de los temas principales de su obra. Rivas es despiadado en su crítica al llamar la atención del lector constantemente sobre este detalle desafortunado de la vida del ilustre escritor. Hasta el nombre del poeta, S. C. Mata (ése se mata), es una alusión al suicidio.

La frívola preferencia de Mata por los dioses de la antigua religión egipcia, tal como se ve en "Nostalgia egipcia", alude al escepticismo religioso de Silva. Este interés por los dioses paganos no es importante en sí; sólo demuestra su rechazo del cristianismo y la falta de una verdadera creencia religiosa. Rivas Groot insinúa que su falta de fe religiosa cristiana (representada por su excesiva afición a una religión pagana), fue un factor importante en su decisión de quitarse la vida. Esta es una opinión mantenida por algunos respecto a Silva. ${ }^{8}$

Es curioso notar que los motivos egipcios están tomados de la ópera Aida, ${ }^{9}$ y que precisamente durante una representación de esta obra se suicida Mata, cumpliéndose así su deseo de morir en medio de 'los vestigios de aquella civilización pagana.

Toda la poesía de Mata demuestra la preocupación mótbida de éste por la muerte, y tiene por objeto mofarse del cristianismo. Veamos otros ejemplos:

Cubran, pues, mi cadáver las arenas del nubio

Arenal, como pliegues de un gran sudario rubio

$\mathrm{Y}$ en vez de sacerdotes de hipócrates suspiros,

Récenme roncos bonzos, rezando en sus papiros. (p. 78)

En vez de cruz y de latines, quiero magníficos

Signos sobre mi lápida con ocres jeroglíficos.

En vez de los requiescat en caracteres góticos

Quiero los sugestivos caracteres demóticos

hallan en los capítulos sobre Mata, recuetdan el estilo de Rivas Groot en Resuvección y El triunfo de la vida. Por lo tanto, nos parece justificado atribuir la creación de la figura del poeta Mata a Rivas Groot, sobre todo en lo concerniente a las parodias literarias. Es indudable que muchas de las otras referencias, por ejemplo, las políticas, deben imputarse a Marroquín.

8 Véase Alberto Miramón, José Asunción Silva, $2^{*}$ ed., Biblioteca de Autores Colombianos, $\mathrm{n}^{\circ} 110$ (Bogotá, 1957), p. 126.

$\theta$ Compárese esta descripción del escenario de la ópera con el poema: "El palacio del rey en Menfis; a la derecha e izquierda, inmensas columnatas, las estatuas de los dioses: Keth, la divina gata; Ra, el gran dios del dominio; Patch, con su testa de leona; el Buey Apis, el bruto más santo de los brutos. En el fondo, a través de grandes pórticos egipcios, el desierto, las pirámides, la. Esfinge" (p. 291). 
Con sus hierogramatas y erizados criocéfalos

Abuelos decadentes de los griegos bucéfalos

$\mathrm{Y}$ el cuerno funerario de cariñosa Osiris

Que juega con las danzas estéticas del Iris. (p. 78)

Donde se hacen todavía más patentes las alusiones literarias de Pax es en el poema "Balada de la desesperanza". La crítica ha señalado que se trata de una parodia del famoso "Nocturno" de Silva y de "Palemón el estilita" de Valencia. ${ }^{10}$ En general, el verso libre remeda el del "Nocturno", y el asunto, la historia de un monje que se suicida porque teme sucumbir a los hechizos de una dama ilustre, tiene como punto de partida el asunto de "Palemón el estilita" (la historia de un monje que se rinde a los encantos de una cortesana); pero Rivas Groot altera el final del poema para que Silva sea el blanco de su ironía. En los motivos y vocabulario utilizados hay numerosas alusiones a ambos autores.

Examinemos la "Balada de la desesperanza". Al ver su irregularidad métrica, con la alternancia de versos cortos y largos, pensamos inmediatamente en el "Nocturno":

Fray Martín de la Cogulla,

El prior de Calatrava,

Que agotó las penitencias, los cilicios, los ayunos, asperezas, disciplinas, y con garfios

Desgarró sus carnes pálidas,

Castigó sus apetitos, .................. (p. 122)

Para mofarse de las innovaciones métricas de Silva, Rivas Groot extrema su procedimiento haciendo que haya versos de sólo dos sílabas, y otros de cuarenta y seis.

Una de las técnicas más eficaces del "Nocturno" es la repetición; Rivas Groot parodia el procedimiento mediante el simple cambio de posición de los términos:

Dominaba

Las pasiones de alma y cuerpo,

Cuerpo y alma,

$\mathrm{Y}$ era un monje venerable con su barba larga y noble,

Noble y larga. (p. 122)

10 Uno de los primeros en advertir la parodia fue Julio H. Palacio, "Pax y uno de sus críticos", El Nuevo Tiempo (Bogotá), 2 de julio de 1907. 
También se burla Rivas de la repetición al parodiar los primeros renglones del "Nocturno" ("Una noche, / Una noche toda llena de perfumes, de murmullos y de música de alas, / Una noche en que ardian..."):

Una noche,

Una noche,

A la una, a las dos de la mañana,

A la una,

A las dos,

A las tres de la mañana,

................... 123)

Lo sublime de la expresión de Silva queda aquí en ridículo a fuerza de añadirle detalles particularizadores.

Pero donde más despiadadamente se remeda la técnica de la repetición es hacia el final del poema, cuando el monje sube a la torre del convento para alli suicidarse:

El anciano penitente, fray Martín de la Cogulla

Fue a la torre, y una grada,

Después otra,

Y otra grada,

$Y$ otra grada,

$Y$ otra grada,

Fue subiendo

........... (p. 125)

El grotesco final de la "Balada" encierra varias alusiones muy concretas al "Nocturno":

Con la cuerda que en el cinto le estrechaba

El buen fraile jcrac! se cuelga;

$Y$ en las cales de la torre

Proyectadas

Por los rayos

Gris y plata

De la luna,

Se estiraban

La capucha,

$Y$ las canas,

Los toisones

De la barba

$Y$ las vértebras,

La sarga,

$Y$ los pies,

$Y$ las sandalias,

$Y$ la cuerda, 


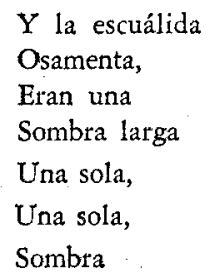

Larga. (pp. 125-126)

La frase de Silva, "Y mi sombra / Por los rayos de la luna proyectada", halla eco aquí en la sombra del monje suicida, también proyectada por los rayos de la luna. La repetición del copulativo "Y" al principio del verso es asimismo una reminiscencia del "Nocturno". Finalmente, no hay necesidad de llamar la atención sobre la suprema ironía con que concluye la "Balada": en el "Nocturno" la sombra del autor se funde con la de su amada, " $Y Y$ eran una sola sombra larga!"; aquí los componentes de la sombra son el cuerpo y la vestimenta grotescamente estirados del fraile suicida.

Se pueden señalar otros elementos - frases o palabras sueltas- que Rivas Groot tomó del "Nocturno" o de "Palemón el estilita", y que no dejan lugar a dudas respecto al blanco de sus dardos. En el "Nocturno" se oye "el chillido / De las ranas"; en la "Balada" fray Martín está desvelado "Por las ranas que en los fosos del convento / Crotoraban", En "Palemón" el diseño de las manos de la "linda pecadora" que seduce al protagonista "semejaba lotos vivos"; en la "Balada" leemos "la be1la / Doña Sancha / Semejaba un loto vivo". Otras palabras poco usadas que seguramente tomó Rivas Groot de "Palemón" son el adverbio "despacito" y los nombres "ayuno" y "cilicio".

Como ejemplo de la prosa de Mata se nos lee un trozo de su Evangelio del Blasfemo. Aquí se parodia el nietzscbismo, ${ }^{11}$ con su negación de Dios y su exaltación del hombre como ser supremo: "Viajaba el Sobrehumano por una landa desierta, sin sol y sin árboles. Su sombre no lo seguía. El seguía a su sombra. Atravesaba el caos sangriento... Y dijo el Sobrehumano: Os anuncio la buena nueva. He matado lo supraterrestre; he matado el amor; he matado el alma... No creáis

11 Parece que en el Bogotá de fines de siglo había una sociedad secreta llamada "la Pagoda de Nietzsche", dedicada a la difusión de las ideas del ilustre escéptico alemán. Rivas Groot ya había tratado este tema anteriormente en "Un discípulo de Nietzsche". En este cuento también se presenta un joven poeta que se ha desorientado leyendo a Nietzsche, y quien se ha entregado a escribir poesías de fuerte sabor decadentista, cuyos motivos principales se toman de la antigua religión de los egipcios. 
a los farsantes ermitaños que os hablan de lo supraterrestre, del alma, del amor... No hay más que un Dios: el hombre Sobrehumano. ¿No veis los tres cadáveres de los tres grandes Muertos? ¿No os apesta la putrefacción de las cosas divinas?... ¡Por encima del bien y del mal, por encima de la Verdad y la Mentira, por encima de esos grandes Muertos, no queda ya en pie sino el Yo Sobrehumano!" (pp. 28-29).

Es sabida la profunda influencia que Nietzsche tuvo sobre Silva. ${ }^{12}$ Su orientación filosófica, "mezcla de nihilismo y de afirmación vital del instinto, de escepticismo religioso...",13 se refleja en sus poesías denominadas "Gotas amargas" y, sobre todo, en su novela autobiográfica, De sobremesa. Naturalmente, estas creencias no se manifiestan de una manera tan cruda y poca artística como la parodia aquí reproducida; por lo tanto no es posible señalar ningún original para el pasaje atribuido a Mata. Probablemente el punto de partida más inmediato de la parodia son los poemas "La respuesta de Ia tierra", "Psicoterapéutica", "Futura" y "Filosofías".

En las páginas siguientes se nos sigue presentando el retrato de $\mathrm{S}$. C. Mata. De acuerdo con la tradición de los poetas decadentes, abusa de las drogas; en varias ocasiones lo vemos aplicarse inyecciones de morfina (pp. 78, III, 299). Pero al contrario de los poetas que se encierran en su torre de marfil, Mata es hombre activo en la política y en los circulos sociales. Se pone a las órdenes dél revolucionario Landáburo y lo adula de la manera más zalamera. Lejos de considerarse un poeta selecto, Mata busca los aplausos del vulgo, recitando sus versos en los banquetes políticos y en cualquier otro sitio donde se le quiera escuchar. Es un ególatra insoportable; fuera de recitar sus versos con cualquier pretexto no hace más que hablar de su próximo tomo de poesías. ${ }^{114}$ Tiene el descaro de pedirle al millonario Ramón de Montellano que le costee una edición de sus poesías, a pesar de que Montellano no conoce ni las poesías ni el autor. $\mathrm{Y}$ circula entre sus amigos una petición al gobierno, cuyo objeto es la publicación de sus obras. En este documento se llama a sí mismo un "Homero colombiano", "el más inspirado de los poetas de Hispanoamérica, ...ingenio auténtico,

12 Véase Rafael Maya, Introducción a José Asunción Silva, Obra completa, $2^{2}$ ed., Biblioteca de Autores Colombianos, $\mathrm{n}^{\circ} 99$ (Bogotá, 1956), p. 16.

13 Ibid.

14 Estos tomos incluyen: Nitroglicerinas, Oriente eterno, Amor dionisiaco, Mi Pentateuco, Lineas rojas y El cantar de mis cantares, títulos todos que parodian el nihilismo y el escepticismo del pensamiento de Silva. 
que está a cien codos por encima de todos los escritores vivos y comparable sólo a uno o dos de los muertos..." (pp. I65-I66).

Desde luego, estas características del poeta S. C. Mata nada tienen que ver con lo que era el hombre José Asunción Silva. Ninguno de sus biógrafos sugiere que Silva fuera un morfinómano, bien que es verdad que su alter ego, el José Fernández de De sobremesa, es víctima de las drogas. En cuanto a que pusiera su voz a las órdenes de un dictador o de un partido político (como un Darío, por ejemplo), basta con una ojeada a su obra para desechar tal acusación. Menos aún se puede decir que buscara la aprobación del populacho o de la crítica. Silva era el prototipo del artista introvertido y reconcentrado; por lo general, recitaba sus versos sólo en la compañía de unos amigos íntimos, y despreciaba profundamente a los poetas aplaudidos de su tiempo, como Núñez de Arce.

El capítulo XXII de Pax se titula "S. C. Mata" y presenta el suicidio dél poeta. Este se quita la vida durante una representación de Aida. Su poema "Nostalgia egipcia" es un puro calco de los motivos egipcios de la ópera, pero el poeta ha olvidado esto y, ya en el borde de la locura, cree que él y Verdi son "hermanos del alma", genios que han coincidido en el pensar. Transportado por los arrebatos de la música, Mata declara su amor a la cantante que desempeña el papel de Aida. Ella lo rechaza con desprecio. Corrido por su fracaso, el poeta decide quitarse la vida a la entrada del escenario, pensando que su cuerpo caerá hacia la luz y así llamará la atención de todo el mundo. Pero en vez de morir en forma tan dramática, su cuerpo cae entre dos bastidores, de donde es arrastrado ignominiosamente hacia un rincón por un tramoyista que cree que se trata de un borracho. Allí permanece, ignorado de todos, hasta después de caer el telón.

El sarcasmo final de Rivas Groot y Marroquin no ha podido ser más aplastante. La ridícula figura del poetastro queda completamente aniquilada al fallar su pretensión de despedirse de la vida con un gesto grandioso y dramático. No es necesario apuntar la divergencia entre la grotesca muerte del personaje novelesco y el fin trágico de José Asunción Silva; para quitarse la vida éste buscó el silencio de su alcoba, lejos del tráfico humano.

Para concluir, diremos que es innegable que los autores de $P a x$ quisieron caricaturizar al gran bardo colombiano en la figura de S. C. Mata, como sc echa de ver en las numerosas alusiones a su obra y a su persona. Pero al trazar el carácter de su víctima, se dejan llevar de sus 
antipatías personales $y$ atribuyen a su creación literaria defectos que no existian en el original humano. De modo que el poeta Mata es algo más que una caricatura de Silva; es una como síntesis de todos los rasgos malos que pueden darse en un artista.

Donald MCGrady

University of Texas 